\title{
Beyond competitive intelligence - innovation and competitive strategy
}

\author{
Marié-Luce Muller \\ IBIS Business and Information Services \\ mlm@ibis.co.za \\ www.ibis.co.za
}

\section{Introduction}

Having over the past two years provided the basic how-to of competitive intelligence (CI), the time has come to move beyond these basics of $\mathrm{CI}$ to examine the true value and purpose of CI. CI has also moved beyond answering questions relating to its value and purpose.

CI really took root in South Africa in the mid-1990s and early 2000s. While there are a myriad companies only now starting to take better cognizance of their external competitive environment, it is also true that many companies and institutions in all industries have developed sophisticated CI capabilities and are moving beyond the implementation and refining phases to recognizing CI for its true purpose, namely as a constant radar on the lookout for opportunities and threats, a tool to enhance company knowledge and promote innovation and a constant input in strategic decision making.

That is the true role, value and place of CI.

The next few articles will deal with this high-level value of CI. The basic elements of CI, what it is, what it is not and how companies can ensure effective CI can be read in previous Competitive Intelligence columns in the South African Journal for Information

Management.

\section{True purpose of CI: strategic value}

CI's main aim is to provide a company with a competitive advantage by providing input to a competitive strategy. There are of course CI benefits in other levels of a company, but these should not overshadow the true purpose. Many businesses grow content in their development because they forget the importance of continuous effort to differentiate, adapt, change or become more profitable (through innovative processes, products and services) (Williams 2004). CI is a way to alert companies constantly of changes in the competitive environment.

In his article, 'Industry risk management: CI's next step', Gilad (2001) states that 'the purpose of a CI program is to develop action-oriented implications for managers'. Intelligence also needs to be delivered on a timely basis so it can be incorporated into the decision-making process (actioned). Action-oriented CI programmes have been shown to lead to positive organizational and individual outcomes (APQC 1996; 1997). The process of CI involves the development of intelligence products, their flow to decision makers on a 
timely basis, and the incorporation of said intelligence into the decision-making process.

Research has shown that CI capabilities typically develop through different stages. Figure 1 illustrates the ultimate place of CI, namely as a risk management and early warning tool that alerts managers to risks in order for them to be able to minimize that risk (Gilad 2001).

Figure 1 Stages in the development of CI

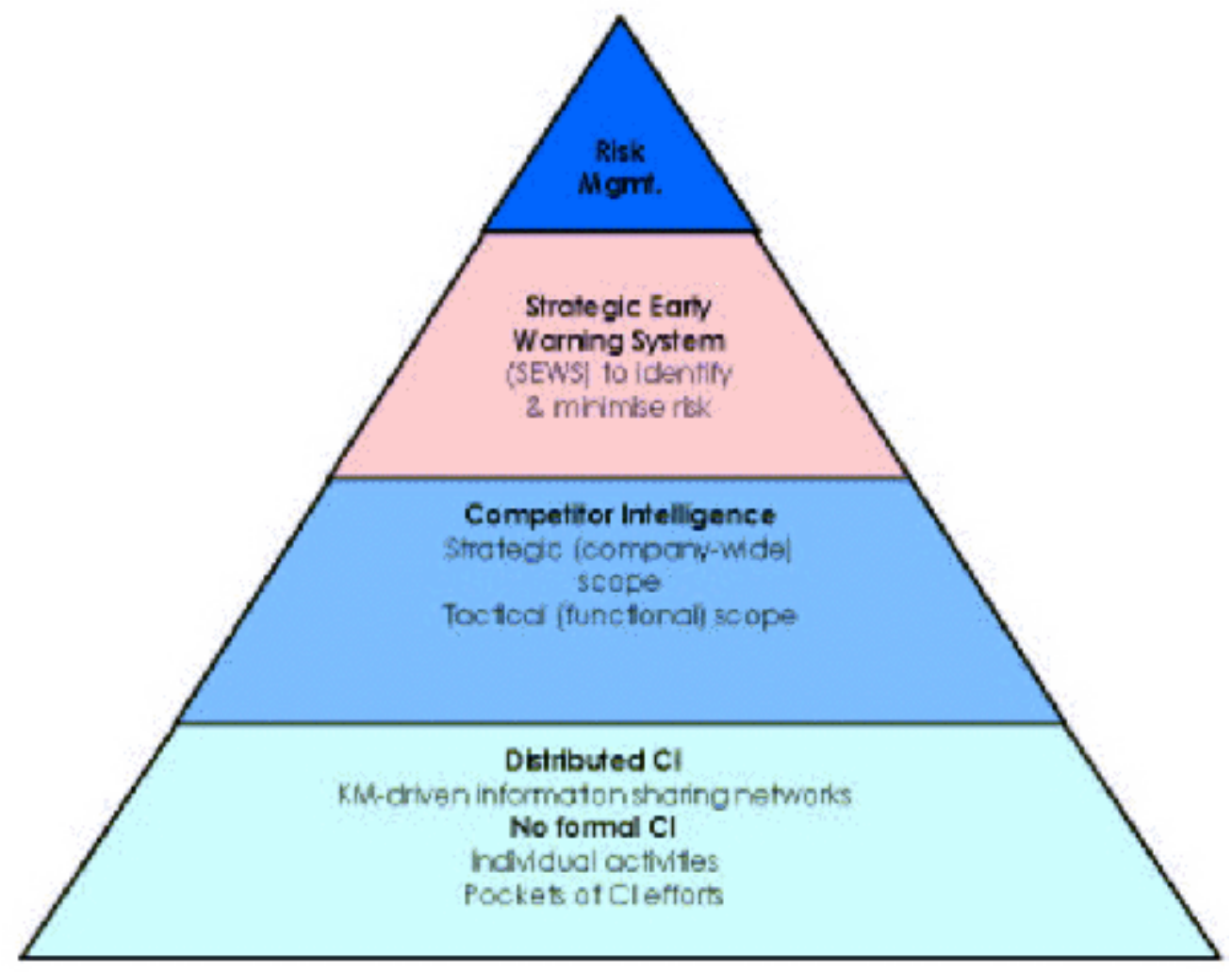

\section{No formal CI}

CI development undergoes various development phases starting as an informal small capability on business unit level and developing to become a source of strategic knowledge. Whereas early CI occurred through the 1960s and 1970s (focusing more on information gathering), the CI of the 1980s progressed to include industry and competitor analysis ( Prescott 1999). Current CI is beyond that - it is CI for strategic planning and CI as a core competence.

Although some sophistication developed over time and more structure and focus were added (perhaps even elevated to a higher level and gaining a custodian status and some form of management), most current CI capabilities remain stuck in the information business and have failed to become strategy advisory bodies.

Gilad (2000) states that many corporate CI operations have been experiencing demise due to bureaucracy. The problem can be related to the failure of CI to provide strategic value rather than becoming a market research capability or a knowledge management function, as is so often the case in South African companies.

When certain success factors are present (e.g. top management support and utilization of CI, the right people involved in CI and the existence of a competitive culture), CI's role and purpose assumes its real value. This value is hard earned and needs to remain intact, and here the CI practitioners' responsibility in keeping CI at that top level is big. CI needs to 
continuously demonstrate value or company managers will not be convinced of its purpose. According to Gilad, it is the industry and business risk management role of $\mathrm{CI}$ that is elevating it to its ultimate value (Gilad 2001).

Gilad states emphatically that CI practitioners 'are not information professionals nor information service providers'. This must surely ring a bell for many a frustrated CI practitioner in South African companies. 'In reality, CI practitioners are not even in the field of information. They use information coming from a balanced source infrastructure that feeds on human sources, and rely on internal and external networks' (Gilad 2001). CI professionals simply apply information and intelligence when identifying, monitoring and warning of risks and opportunities and changes in the business environment (relating to customers, products, new inventions, mergers, takeovers, etc.).

Unless companies have a capability to continuously track and scan change, identify risk and monitor risk, they will be unable to manage risk, identity opportunities, avert threats and decide on an appropriate strategy. Using a professional sophisticated CI function to focus only on competitor or customer activities would be a waste of CI. CI's interest comes into play when it is able to identify a new pattern of behaviour in a competitor, interpret this as a possible change in strategy and alert decision makers to the need of adjusting plans or direction.

$\mathrm{CI}$ in this strategic risk management role should be able to make recommendations for strategic adjustment and likely scenarios. The CI capability should continue measuring the impact of new strategies. Gilad cites the example of a company where the CI professional was given the power to coordinate a competitive response. Palm nominated a chief competitive officer (CCO), with the purpose of developing a whole range of coordinated responses to Microsoft's entry into its market - from an overhaul of marketing strategy to accelerated development activities. This suggests that a high-level, coordinated approach to a significant structural change (in this case from a major new competitor) is the way to go (Gilad 2001).

\section{Value measurement remains a challenge}

Many CI capabilities have difficulty in forecasting possible returns on investments. This leads to reluctance among managers to invest in CI (Kilmetz and Bridge 1999). Of course, the more CI can demonstrate value (albeit indirect), the more resources are made available there is a significant responsibility on CI practitioners to deliver strategic, value-actionable intelligence. When questions are asked about the true value of CI impacted on the resources allocated to the capability, those who could not demonstrate value soon faced demise or relegation to research level for the product manager or the marketing division. Prescott states that, while there was evidence that CI efforts assisted in the sharing of ideas, sensitized managers to the value of addressing competitive dynamics, identified new business opportunities and avoided surprises, there was a lack of consensus on how it influenced the bottom line and whether it was user-oriented (Prescott and Fleisher 1991; Barndt 1994). ( More about the measurement of the value of CI in the next article.)

\section{Growing top-level status of CI involves effective management of CI}

Owing to increased competitiveness and the need to constantly differentiate (through perpetual innovation) in a market dictated by consumers, the field of CI has grown over the past two decades to become an integral part of most large organizations (Fuld 1995; Kahaner 1996; McKinnon and Burns 1992). Access to and gathering of information is no longer sufficient - even analysing and interpreting information is no guarantee to competitive advantage. How CI is communicated (in actionable format) to those who take 
strategic decisions about a company's future, and how they use the intelligence, determines the winners and losers in the competitive battlefield. Intense competition is the best motivator for CI growth, sophistication and elevation.

Although not prevalent, there are many companies, locally and internationally, that boast effective high-level CI capabilities. Leading-edge CI capabilities can be characterized as follows (Fuld 1995):

- The CI unit has a well-developed, formalized process and network.

- There exists a strong link to the users of intelligence, who primarily dictate and fund the types of projects undertaken.

- There often is sophisticated analysis involving a combination of both quantitative and qualitative data.

- A significant number of projects are oriented towards strategic decisions although CI, as a company-wide resource, also demonstrates value at business level.

- Top management explicitly recognizes the value of CI and links it directly to the decision-making process.

Ensuring that the right intelligence is forthcoming from the CI capability and that the focus of the CI process is accurate is mainly a managerial issue concerning the intelligence process. As mentioned in previous articles on the topic, this focus is provided by management's key intelligence needs (KIN). The process then follows routine steps, each involving careful planning and management, namely collecting information, analysing information and interpreting and communicating the analysed information (intelligence.) Ultimately, CI is the result of producing implications and recommendations for managers (Prescott 1999). Throughout the intelligence cycle, feedback and updates from CI professionals allow for midcourse adjustments and new issues to surface. Furthermore, the proactive CI professional brings intelligence issues to the attention of managers.

\section{CI will continue to become institutionalized in the business community}

Prescott provides a description of how the leading-edge companies of the future will use CI:

'The CI process within a multinational company is institutionalized on a worldwide basis although there is local responsiveness. The vast majorities of the employees appreciate the value of CI and participate in the process including counter-intelligence efforts. Data analysis is extensive with qualitative input often dominating quantitative data. The intelligence is integrated directly into strategic decisions often through sophisticated information systems. Top management uses CI as one of the ways it shapes the future of the organization and considers it an integral part of the learning organization. A key component of the companies of the future is that managing behavioural dimensions of CI becomes critical. While collection and analysis are important, how organizations mobilize the informal CI process will determine their effectiveness.'

\section{References}

APQC (American Productivity and Quality Center). 1996. Leveraging information for action. Houston, TX.

APQC (American Productivity and Quality Center). 1997. Managing competitive intelligence knowledge. Houston, TX. 
Barndt, W.D., Jr. 1994. User directed competitive intelligence. New York: Quorum Books.

Fuld, L. M. 1985. Competitor intelligence: how to get it; how to use it. New York: John Wiley \& Sons.

Gilad, B. 2000. An ad hoc, entrepreneurial CI model. Competitive Intelligence Magazine Oct/Dec 3 (4).

Gilad, B. 2001. Industry risk management: CI's next step. Competitive Intelligence Magazine May/June 4 (3):21-27.

Kahaner, L. 1996. Competitive intelligence: from black ops to boardrooms. how businesses gather, analyze, and use information to succeed in the global marketplace. New York: Simon and Schuster.

Kilmetz D.S. and Bridge, S.R. 1999. Gauging the returns on investment in competitive intelligence: a three-step analysis for executive decision-makers. Competitive Intelligence Review 10(1).

McKinnon, S. and W. Burns. 1992. The information mosaic. Boston: Harvard Business School Press.

Prescott , J.E. 1999. The evolution of competitive intelligence. Proposal Management 37-52 (Spring).

Prescott , J.E. and Fleisher, C. 1991. SCIP: who we are, what we do. Competitive Intelligence Review 2(1):22-26.

Williams, C. 2004. Building your competitive advantage into your agenda. [Online]. Available: http://innovation.articleinsider.com/56582_competitive_advantage.html (Accessed 25 January 2005).

\begin{abstract}
About the author
Marié-Luce Muller is a consulting competitive intelligence analyst with IBIS Business and Information Services (Pty) Ltd, a leading Pretoria-based CI consultancy. She has a distinguished career in competitive intelligence. Her primary experience lies in assisting companies in honing their CI capabilities. She also performs tracking and scanning activities on behalf of companies. Marié-Luce has published many articles on competitive intelligence (CEO Magazine, Finance Week, Business Week, Beeld, Die Burger, and the South African Journal of Business Management), including an article on South Africa as an emerging CI player, which was published in an international publication of the Society of Competitive Intelligence Professionals (SCIP). She has also published a series of booklets on competitive intelligence (Nuts and Bolts business series, published by Knowledge Resources) and is a member of a research team participating in an international study of competitive intelligence practices among exporting companies. Previously, she was involved in research into the status of competitive intelligence practices in South Africa. A member of SCIP, she holds a postgraduate degree from the University of Stellenbosch.
\end{abstract}

\title{
Disclaimer
}

Articles published in SAJIM are the opinions of the authors and do not necessarily reflect the opinion of the Editor, Board, Publisher, Webmaster or the Rand Afrikaans University. The user hereby waives any claim he/she/they may have or acquire against the publisher, its suppliers, 
licensees and sub licensees and indemnifies all said persons from any claims, lawsuits, proceedings, costs, special, incidental, consequential or indirect damages, including damages for loss of profits, loss of business or downtime arising out of or relating to the user's use of the Website.

ISSN 1560-683X

Published by InterWord Communications for the Centre for Research in Web-based Applications, Rand Afrikaans University 